\title{
The Challenge of Mai Chung: \\ Teaching Technical Writing to the Foreign-Born Professional in Industry
}

SHERYL PEARSON

University of Michigan, Dearborn

\begin{abstract}
Because of the growing numbers of foreign-born technical professionals in American industry, the need for appropriate on-site instruction in the English of Science and Technology (EST) is becoming urgent. However, what the working professional needs from a course in writing EST differs markedly from what the university student in a technical degree program needs. This article identifies the most important of these differences and their implications for course design and materials development. It also argues that recent research on the dynamics of reading technical English can be used to inform the teaching of the technical writing skills that non-native speakers of English require in industry settings.
\end{abstract}

The main work I am doing is programing in data base system. Except to writing the program I have to put comments to my program shortly and clearly. When design a new command we are required to do the system documentation about the system is designed for the walk through. It is hard for me to write down and let people understand what I intend to do neatly and straight forward.

-from an answer to a questionnaire

\section{WHO IS MAI CHUNG?}

The statement above was made by a foreign-born computer services professional who participated in one of my industry seminars in technical writing. Although her English is nonstandard, she is a valued programmer to her company and a specialist in machine languages. Both her supervisor and she herself recognize that for her to fulfill her promise, however, she will have to become more proficient in the written English "metalanguage" of her field-communication about her work, especially to co-workers who have less expertise in her specialty than she has or to those with limited knowledge of her assigned tasks. Improving this area of her professional function will involve instruction not only in the structural and 
mechanical areas in which her weaknesses are immediately apparent, but also in the rhetoric of the specialized message formats peculiar to her job.

To preserve the privacy of the young woman whose questionnaire I have quoted from, I will refer to her as "Mai Chung," When hired, Mai Chung had had no specialized training in writing any of the documents that her job required, documents described by one of her nativespeaking co-workers as including "operators' manuals, minutes of meetings, functional descriptions, internal memos, project proposals, status reports, interface specifications, and internal program documentation." Mai Chung is one of the many practicing foreign-born professionals who, despite strong technical credentials, find that their proficiency in the English of Science and Technology (EST) is marginal or uneven enough to cause unsatisfactory performance and real anxiety on the job. Many seek out company-sponsored workshops in technical writing, such as the ones I conduct. Although these courses are usually open to both native and non-native speakers of English, it is the foreign-born participant who has the greatest stake in the success of the instruction.

Non-native English-speaking professionals like Mai Chung (hereafter called non-native professionals, writers, or learners) enroll in these courses accepting the implicit promise that certain indispensable writing skills can be taught. It is therefore important that we deliberately assess the challenge that teaching such writing skills presents to the EFL specialist.

The special difficulties that readers face in decoding EST texts implicitly define skills that EST writers, native or non-native, need to master and that EST courses for the non-native learner need to address. The literature in rhetorical theory has for some time stressed the intertwining of the reading and writing experience, a connection that has only recently become the subject of exploration in the applied linguistics research that touches on the teaching of technical English. A useful article that addresses this central connection in general terms is Dubin and Olshtain's "The Interface of Writing and Reading" (1980). Like Dubin and Olshtain, I proceed on the assumption that writing and reading are complementary and reciprocative functions. However, while these authors seek to determine what a knowledge of English writing processes can tell us about teaching reading strategies, I approach the connection from the opposite point of view. In the context of teaching technical writing, I argue, the more writers understand about the special demands placed on readers by a complex text, the more sensitive the writers will be to the composing decisions that affect the readability, clarity, and proficiency of their own 
English. I also argue here that EST learners in industry are a distinct class of both EFL students and technical writing students and that observations in much of the current literature on EST (which tends to focus on conventional EST learners as university students) transfer only indirectly to the teaching of EST learners who are already practicing professionals.

This article offers some suggestions for adapting the available literature on EST for teaching this unique clientele. I begin by noting some of the high points in the relevant research on technical discourse to see what it tells us about teaching EST as a distinct mode of discourse. Next, I address the question, "What is distinctive about the foreign EST learner in industry?" And then I conclude by sharing some suggestions for meeting the special needs of this learner group, especially in their role as technical writers.

Mai Chung is part of a growing number of non-native technicians and professionals currently employed in American business and industry who are discernibly handicapped by their lack of proficiency in the highly specialized technical writing skills required by their work. Recent labor statistics confirm that the crisis caused by the severe shortage of American technical professionals (especially in engineering) that began in the 1970s has been eased partly by a surge in the domestic employment of foreign-born technical personnel. Many of these professionals have received their advanced technical education in the United States. A few recent statistics reveal some of the dimensions of this phenomenon:

- According to the latest annual census of foreign students conducted by the New York-based Institute of International Education, there were 326,299 foreign students enrolled in American colleges and universities in 1981-82. This figure represents a $4.6 \%$ increase over the previous year and $2.6 \%$ of the total student enrollment at institutions in the United States. The largest number of foreign students-25\% of the total-were in engineering, with business and management the next most popular fields (Scully 1982).

- Foreign students earn a third of all advanced engineering degrees awarded in the United States (Peer and Howard 1980).

- According to National Science Foundation figures, "although the number of engineering Ph.D.'s awarded by United States schools dropped 20 percent from 1974 to 1980 , the proportion of those degrees awarded to foreign students increased to 46.3 percent from 38.7 percent. That is up from 19.8 percent in 1964" (Chesser 1981:13).

- According to a 1978 Labor Department study (the most recent available), one out of three foreign students stayed in the United States after graduation (Greer 1983). 
- American universities cannot turn out trained technical professionals fast enough to keep up with the demand, which in some rapidly growing fields is severe. For example, the Bechtel Group of San Francisco estimates that there will be 80,000 industry-wide openings for synfuels engineers alone by the end of the 1980s (Peer and Howard 1980). According to a 1981 study of 610 companies by the American Electronics Association, there will be "an annual shortfall of 20,000 engineering graduates in electrical and computer science engineering through 1985" (Greer 1983:73).

- Fewer American students are seeking advanced technical degrees in American universities, "and their places in the classroom and later in highly trained spots in industry are being filled by foreigners" (Chesser 1981:13). According to statistics released by the Labor Department, certifications "issued to foreign engineers seeking resident alien status over the last five years rose 118 percent ... while those issued to physical scientists, including physicists and chemists, rose 13 percent over the same period... Mathematicians [including computer scientists, rose] 15 percent" (Chesser 1981:13).

Mai Chung is clearly not alone. In fact, her name is legion.

\section{RECENT RESEARCH}

Fortunately, there have been some very promising lines of investigation in recent research on technical discourse, some of direct relevance for the EFL classroom. Probably the best known theoretical work in this area in the last few years has been that of Larry Selinker, Louis and Mary Todd Trimble, John Lackstrom, Robert Vroman, and others on such subjects as categories of technical discourse functions, presupposition in technical discourse, anaphoric substitutions, rhetorical focus and predication, and the differential function of implicit and explicit information in technical discourse (see Selinker, Todd-Trimble, and Trimble 1976, 1978; Lackstrom, Selinker, and Trimble 1970, 1973; Selinker, Trimble, and Vroman 1974). This body of research has offered some useful observations on classes of technical rhetoric and on hierarchies of particular rhetorical functions in technical discourse. Applications have been addressed by Richard Young (1979), Robert de Beaugrande (1977), Dwight Stevenson (1977), and J.C. Mathes (1980), who, among many others, have concentrated on writer-oriented questions of problem definition, audience analysis, coherence, devices for ordering paragraphs, and rhetorical purpose, Mathes and Stevenson (1976) have also worked out teachable heuristics for rhetorical invention in technical report writing and algorithms for selecting, segmenting, sequencing, and editing technical information according to rhetorical purpose. There is also now a growing number of textbooks devoted to EST training, some academic in focus and some vocational 
(generally devoted to specific fields such as public health, banking, or electrical engineering). ${ }^{1}$

Looking at the tasks involved in reading EST offers a useful introduction to the subject of EST writing in industry because it is crucial for foreign-born professionals to be able to translate what they know about readers' diverse needs and expectations in a given organizational setting into specific guidelines for composing. Selinker (1979), among others, has raised issues that bear directly on the specific problems of the foreign-born professional. Although Selinker lists areas that native readers of EST would have difficulty with in trying to understand a technical text in a discipline not their own, such problems, by extension, also suggest both questions that non-native English speakers must themselves raise in decoding an advanced technical text and questions that non-native writers must learn to anticipate and satisfactorily answer in their writing. Five of Selinker's categories can be used to investigate areas of difficulty of particular concern to nonnative technical writers in industry: technical terms, common language words used technically, strength of claim, contextual paraphrase, and rhetorical structures. ${ }^{2}$ Each is discussed here in terms of the kinds of composing decisions that writers like Mai Chung must make whenever they prepare technical documents within their organizations.

\section{Technical Terms}

The subject of technical terminology has historically received the greatest attention in the classroom and in the literature about learning technical English. Technical terminology nominally refers to the vocabulary specific to a specialized field, but it also includes a subtechnical lexis that belongs to no one field. Subtechnical terms are those which name the important concepts that are common to many branches of advanced inquiry or problem solving or are inherent in specialized reporting in general (for example, parameter, discrete, comprise, hypothesis, preliminary, corroborate, projected, issue). While learning the core terminology of a field may pose a significant problem for students learning in a university setting, it is of minor consequence for practicing professionals, including non-native ones. In the first place, working professionals will have already mastered the technical concepts on which their work is based and, with that mastery, will have become well versed in the vocabulary of their fields. In the

\footnotetext{
1 Lori Roberts (1981), of Wayne State University's English Language Institute (Detroit, Michigan), has recently surveyed the field of existing textbooks in EST and has prepared a useful but as yet unpublished classification guide for interested teachers.

2 I do not use the remaining four categories that Selinker mentions because the problems they pose for the professional do not differ significantly from those experienced by the traditional EFL student.
} 
second place, their command of the technical terminology will be continuously exercised in the course of their work. In contrast, problems with subtechnical vocabulary loom much larger for foreignborn EST writers in industry than problems with technical vocabulary. However, traditional EST teaching materials, since they are generally oriented to university students, usually make lexical instruction a primary goal, concentrating on the specialized vocabulary of the students' fields. Non-native professionals are not well served by this emphasis.

The category of technical terminology must also include the problem of heavy noun phrases in EST-long or especially dense groups of related words used, usually, as subjects or objects. While these are not strictly technical terms, the heavy noun phrase (especially the compound noun, as in radiation dose computation model, cycle counter diagnostic program, or emissions control monitor) is an acceptable mode of nominalization in technical writing. Hence, the reader or writer of conventional technical prose has to be able to decode these constructions reliably and produce them appropriately, especially when a heavy noun phrase or compound noun is the common name of a frequently used concept in the field. Both interpreting and using these constructions involve sensitivity to word order when a string of modifiers is concerned. Moreover, writers who can easily read and understand heavy or compound nouns may not be able to produce them in correct form.

Finally, the category of technical terms includes the subclass of problems with using abbreviations and acronyms properly. Ambitious EST writers have been known to bewilder even their most astute colleagues with the use of nonstandard, inadequately introduced, or out-of-context abbreviations. I recall the case of one document headed "CPU Plan for CAL79." Its intended readers were mystified by the $C A L 79$, although they readily decoded $C P U$ as "Central Processing Unit." On being questioned, the writer of the document innocently explained that, of course, CAL79 meant "calendar year 1979." He had elevated a private shorthand to the status of a common technical abbreviation, with an inevitable falloff in communication. Another document contained the following:

Convert SEX (system exerciser) to operate under Standalone, utilizing a RAD/LESS or HAD system, Honeywell or AMPEX memory, and VICTOR disk, an STC VICTOR configuration, and a single or dual CPU configuration.

In this case, despite the density of technical abbreviations, each term or acronym was clear to the intended readers, either because it was a standard, familiar form or because (in the case of SEX, which was an ad hoc coinage) it was immediately expanded on the first use. Non- 
native technical writers of English need to be deliberately cautioned against using reduced terms unless they are known to be accepted forms that are in general use in internal company documents, are explicitly defined at first mention, or are immediately clear from context.

\section{Common Language Words Used Technically}

My own favorite example of this phenomenon is the term charm as used in nuclear physics to denote a poorly understood quality of subatomic particles. Other examples from the computer services firms of my own experience are technical uses of host, architecture, menu, documentation, and protocol, Non-technical words used technically would understandably create interpretation problems for uninitiated readers (those unconversant with the subject matter of the field); however, for initiated writers (that is, writers with the technical grounding we presuppose in practicing professionals, whatever their language background) such terms are easily manipulated. Indeed, they are no more problematic than primary technical terms for the EST writer.

However, items in this class can become troublesome for the reader when combined with uses in the non-technical sense or when used in varying collocations: for example, user documentation, internal documentation, vendor documentation, technical documentation, documentation of sources, program documentation. Which ones are synonyms and which are names for different classes of documentation? If the writer does not command the distinctions, the usage will mislead the reader, who may assign different meanings to the same words or interpret as synonyms words which are not genuinely synonymous.

To this category should also be added mock-technical terms, that is, words used figuratively or playfully as substitutes for the formal technical terms. This phenomenon usually takes one of two common forms. Native speakers may unexpectedly substitute for the proper technical terms all-purpose generic terms as placeholders. Widget and glitch are fairly familiar examples of this kind of substitution; computer initiates use the term frobnitz (pi. frobnitzem) when they mean a "thing, unspecified." Writers may also use metaphoric terms based on the referent's appearance, functional characteristics, or other source of similarity to something unrelated: woofer and tweeter are examples of such figurative terms that have been adopted into general use, replacing the original "straight" terms. These special uses pose problems for the EST reader and writer because their incidence is lower than that of the conventional terms and because they often depend on a tacit and 
sometimes irreverent analogy that the non-native professional may not make or be able to grasp instantly. Almost always these terms have a parodic or playful quality. They play on conventions of language, etiquette, and perception. They tend to be richly punning, obscene, euphemistic, and metaphoric. In all fields, these two working technical vocabularies (the formal and the informal) coexist, both equally established and specialized, but the latter transmitted largely in the oral tradition or in informal contexts. The non-native professionalwho often learns only the formal technical vocabulary initially-may function adequately as an EST writer without knowing the informal terminology of the field, but may have considerable initial trouble interpreting the mock-technical terms or producing them in appropriate contexts. A recent Time article has sampled the playful technical vocabulary of current computer argot, noting that "even users should grok this cuspy sampler of computerese" (Friedrich 1983:39).

\section{Strength of Claim}

Strength of claim, a crucial function for the EST learner to master, has received little attention in instructional materials. It refers to the degree of commitment that writers have to the truth, authority, objectivity, or conclusiveness of their statements, how far they would push their claims and generalizations, whether or not they might be muting assertions, and whether or not they are personally taking responsibility for the information presented. Fairly similar kinds of statements may signal quite different relationships between writers and their data. The statement It has been suggested that the moon is made of green cheese is not the same kind of assertion as The moon is made of green cheese or The poet says the moon is made of green cheese or The astronaut discovered the moon is made of green cheese. Accordingly, technicians who write test reports saying that The results would seem to indicate an overhaul of the system had better indicate their judgment of the reliability of the test results unless they want such a statement to be taken for a cautious recommendation. In my experience, the non-native technical professional is less likely than the native speaker to grasp that most technical writing involves more than just information transfer; in most American organizational contexts it also involves the assertion of some authorial authority, usually with a persuasive or argumentative edge honed to a calculated degree (see Mathes 1980 for a discussion of this distinction).

Moreover, the non-native professional is less likely to command the range of rhetorical strategies that signal subtleties of strength of claim. Readers who are not sensitive to hedging constructions and to the colorations related to modal use, qualifiers, attribution tags, intensifiers, 
distinctions between factives and nonfactives, and other devices may understand the absolute content of a statement but still not understand why it was made. Writers may have similar handicaps and fail to couch propositions in terms appropriately definitive, cautious, noncommittal, or dismissive, as the situation may demand. EST learners in industry, therefore, need special instruction in these rhetorical devices-linguistic skills not commonly covered or linked in conventional second language teaching.

\section{Contextual Paraphrase}

Contextual paraphrase is the use of more than one word or phrase in a text to refer to the same concept; it can be contrasted with exact repetition of a word. When paraphrasing is excessive, it poses problems in technical discourse because it obscures the reference chains that create coherence. Excessive paraphrase often results from an obedience to a tacit stylistic rule in general English forbidding casual repetition of the same word, a rule that native speakers automatically observe in formal, non-technical English. However, this rule does not extend to literary writing, which has traditionally favored repetition as a rhetorical device for creating emphasis, effect, and dramatic echoes (as in Milton's ringing opening line from Lycidas: "Yet once more, $\mathrm{O}$ ye laurels, and once more"). Technical writers, therefore, often associate lexical repetition with literary style and thus with preciousness; this reinforces their adherence to the general English tendency to avoid repetition. Technical writers who are non-native speakers of English may also bring first language proscriptions against redundancy with them into English; others may employ repetition indiscriminately; and still others may display no pattern or predilection. It becomes necessary to explicitly mention the tacit rule that operates in general English (i.e., avoid gratuitous repetition of the same word) to technical English learners and to discuss its strict limits in technical discourse. Writers who avoid repetition of key words in technical discourse, whether out of adherence to the standards of non-technical discourse, because of first language influences, or because of the literary connotations of repetition, may find that their readers are left with no means of following a complex text.

The subject of contextual paraphrase deserves more attention in teaching materials, perhaps in conjunction with pronominalization, parallel structure, and related coherence strategies. Non-native readers often have trouble following anaphoric chains, particularly when the references vary in syntactic class (e. g., verb to noun, as in repeat and repetition; or noun to pronoun, as in organism and it), level of generality or degree of abstractness (e.g., software and DATAGRID 
program, hardware and cycle-counter, staff and programmer), or other qualities such as number, case, or (with verbs) tense.

Even native speakers of English do not always understand that artificially avoiding repetition of the same term can create problems for the reader. Here is an example of a paragraph whose author tried to avoid exact repetition for inappropriate stylistic reasons and ended up using too many terms for the key concepts of the paragraph. The terms that pose potential decoding problems are italicized.

Hand calculation of radiation exposure (dose rate) to individuals due to nuclear power plant operation is extremely long and tedious. To reduce this work load, Mr. James Martin of the Field Operations Division has developed AIREM, a computer dose computational model, to determine radiation exposure. However, before a new technique can be adopted by the division as a standard, it must be demonstrated to be superior to present methods. Consequently, Mr. Martin asked me to familiarize myself with this code so that I may comment on its effectiveness. My purpose in writing this report is to demonstrate the clear superiority of AIREM over present calculation techniques as required for adoption as a divisionalstandard (Mathes and Stevenson 1976, Manual:28).

In negotiating this passage, the reader is forced to determine which of the indicated terms are synonyms or paraphrases for the same concept, which ones indicate a shift in focus, number, or specificity, and which ones denote unrelated, separate concepts. The writer of this paragraph, like many apprentice technical writers, native and non-native, does not yet know that key terms should be repeated.

A related decoding problem occurs when lexical repetition gives a false signal of lexical chaining, suggesting a spurious link to an antecedent term. The following example is taken from a real document written by a participant in one of my industry workshops. In this document, which proposes computer system modifications, the echo of current and currently implies a connection that does not exist. The term currently is contrasted with an implicit future time, after the proposed modifications are made, while the word current is contrasted to previous and describes a line of characters in a visual display.

Escape W, H, and B will not detect line underflow or overflow. That is, if you currently type ESC-16-H when there are only three characters in the current line, you will see \#\#\# and the sequence is aborted with a BELL. Because these functions are handled remotely in PRODATA the extent of the current and previous line will be unknown [emphasis added].

Readers of this kind of technical prose-native or non-native-should not be forced to reread the ambiguous phrases. The passage is already dense enough as a result of the technical content to demand a considerable effort of decoding.

Given the frequency of these kinds of stylistic lapses in native- 
English writers' work, one can imagine the difficulty that non-native writers of technical English have in knowing when to use exact repetition, when to shift to synonym or oblique paraphrase, how much to deviate from the form of the antecedent and still be assured of maintaining reference, how often to re-establish the anaphoric chain, and where in a given syntactic unit to locate the reference. Furthermore, how do such writers determine what rhetorical, syntactic, and semantic factors trigger the need for or the postponement of a reference cue? These concerns arise because teaching technical writing to non-native speakers involves the close interplay of comprehension goals and the language-production goals intimately related to them. And these put a heavier burden on the instructor than the materials available would indicate.

\section{Rhetorical Structures}

Distinct rhetorical or logical structures are dictated by the separate rhetorical purposes of the segments of a text (e. g., technical definition, technical classification, and so forth). These functions can be explicit or implicit. A subclass of questions in this category relates to how shifts in rhetorical purpose are signalled to the reader. This is a key area of concern and one which requires a less traditional (or perhaps less academic) approach to teaching "rhetorical functions." Non-native EST writers may be adequately proficient at conventional describing, classifying, and defining, but uncertain as to how to signal more specific, more relevant, and more shaded rhetorical purposes, such as the following: a veiled criticism, a recommendation for a course of action that is expected to meet resistance, an urgent request, a projected outcome of actions not yet completed, an hypothesis, a ranked array of possible solutions to a problem, a progress report which reports no significant progress, a routine test report that must communicate unexpectedly alarming results, a pro forma trip report, a tentative conclusion based on preliminary data, an unsolicited proposal. These are the kinds of rhetorical functions that professionals encounter in the course of their day-to-day writing tasks, non-native professionals less expertly than native speakers, EST learners need to be urged to identify the precise and various communication purposes of each unit of discourse they write: enumeration, giving reasons, requesting, approving, refusing, and so on. Otherwise, they may find themselves unable to translate high-level, generic rhetorical purposes into particular rhetorical strategies. Existing textbooks do not generally deal with the need for overlapping rhetorical structures and multiple, simultaneous purposes in the kinds of technical documents most often written in organizational settings. 
The preceding survey of EST problem areas is, inevitably, somewhat simplified. However, it provides a convenient means of demonstrating the relationship between reading and writing skills in technical discourse, one that takes into account semantic, syntactic, and rhetorical functions. Furthermore, it forces us to look at the writing tasks faced by the non-native English-speaking professional in industry in the light of the kinds of questions the reader will tacitly ask of the technical text. While it has become common in current rhetorical studies to focus on the reader/writer relationship, the research literature on EST is just beginning to study its implications for language learning and teaching.

\section{THE INDUSTRY PROFESSIONAL AS EST LEARNER}

As already suggested by the previous discussion, non-native EST learners in industry differ in significant ways from non-native university students of EST, especially in the following areas: level of English language proficiency, self-image and relation to instructor, goals, specific intended applications of EST instruction, and type of technical texts to be mastered and manipulated.

In the area of proficiency level, industry professionals are likely to be comparable to university students as advanced users of English for general purposes. However, unlike university students, they will also be highly competent in the specialized technical vocabulary of their fields and hence unlikely to encounter significant difficulty in commanding or using the appropriate technical terminology.

In the area of self-image, industry professionals are likely to see themselves not as students, but rather as either clients or, sometimes, pseudo-employers of the teacher. The teacher, in this setting, is considered either a consultant or someone who offers a service tailored to the users. The instructor is still considered an authority or expert, of course, but more like a hired informant to a professional clientele. This learning model, coupled with the high anxiety that often accompanies the awkward combination of high task competence and marginal communication proficiency on the learners' part, can call for very sensitive handling because it is imperative to preserve the learners' self-image as functioning professionals. In contrast, university students see themselves not only as learners of English but also as preprofessionals. They are thus doubly students. For them, the learning role is more natural, not having the stigma of remediation.

In the important areas of learner-assigned goals and planned applications of EST training, industry professionals usually have in mind highly specific and individualized objectives, They may tell the EST instructor, for example, that they do not want to waste their time studying any grammar because they believe that the office typist will 
take care of grammatical lapses for them. Therefore, they just want to be able to write "version reports" or "status reports" or "specs" or handle internal documentation-each message type, furthermore, likely to be conceived of in a highly stylized company mode. Actually, their deliberateness is an advantage because it helps to focus instruction and to make it purposeful, practical, and legitimate from the learners' point of view. At the same time, this narrowness of perspective may reflect a serious misdiagnosis on the part of the learners of their real writing difficulties. They may, for example, decide that instruction in cohesion and coherence wastes their time because they cannot immediately relate these areas to a desired goal or targeted writing format. Likewise, they may arrive convinced that if they could just learn to command English modals (or relative clauses, or two-word verbs), their writing would be fluent and acceptably correct. Often they are unaware that their written proficiency lags well behind their speaking proficiency, which may be adequate for their professional needs in their present positions. They may not, of course, even have considered whether their communication skills would permit them to be considered for higher-ranking jobs or even to function more effectively in their present ones.

Certainly, foreign university students have specific goals too, and I am exaggerating a little here to underscore my point. But I want to stress the notion-based on close observation of both learner groupsthat university students' and professionals' goals differ in quality and may reflect differences in the learners' self-awareness as EST language users. To reiterate these differences: 1) working professionals are likely to have highly specific goals related to work tasks and productive linguistic activity; university students have more generalized goals related to study skills and to comprehension (mastering an academic data base); 2) by extension, professionals look for evidence of quick progress in productive skills-writing and speaking (although, in terms of speaking, they have probably already demonstrated considerable proficiency by having secured professional employment); students will be relatively more interested in the receptive skills of reading and listening (particularly reading and comprehension of assigned reading materials and to a lesser degree understanding of lecture presentations), especially if they are enrolled in a technical degree program where little extended writing is required; and 3) professionals are likely to convey their other learning objectives in terms of both skills to master and productive errors to overcome, while-and this is somewhat impressionistic, but I believe accurate-students will describe their needs more in terms of generalized end goals (i.e., a desired proficiency level) than specific self-diagnosed areas of difficulty to overcome. Mai Chung was typical of the industry learner in wanting to see EST 
instruction help her to master the particular message formats which posed problems for her as an on-the-job writer.

It should also be said that the tendency for practicing professionals to self-diagnose their language difficulties is fundamentally a valuable trait, even though it sometimes backfires. There is nothing quite so satisfying as working with a student who can thoughtfully identify needs that happen to dovetail with what can be realistically taught. In fact, despite the inherent risks of the associated learner model, we encourage this self-scrutiny in industry workshop participants because it underscores the learners' responsibility for and commitment to their own achievement. Native and non-native learners of EST alike make more meaningful progress when they make an effort to identify their own language needs.

A final area of difference between university students and working professionals concerns the target technical materials that these two groups use. Most of the texts excerpted for analysis in the EFL teaching literature tend to be those academic readings a student would need to study to master the principles, concepts, theories, and basic database central to a technical discipline. Unfortunately, very few EFL textbooks include authentic samples of technical writing as practiced by industry professionals, and fewer still describe the organizational contexts in which they were written. For features such as these, we must seek out standard technical writing textbooks; however, they are designed for native English speakers and do not otherwise meet the needs of non-native learners.

In contrast to the kinds of texts that university students need to study, most documents that technical professionals will generate or encounter are routine, usually short, very concrete, and focused on a single organizational task or technical problem. Moreover, they may be so stylized that teachers as outsiders to industry may initially have trouble locating enough internal rhetorical cues to decipher them, much less teach someone else which cues are redundant or inappropriate and which ones are not. As a result, the instructor cannot always conveniently divorce the teaching of form from the under-

3 While most of the literature has assumed that the non-native EST learners' native Englishspeaking counterparts will deal relatively efficiently with the task of comprehending and generating technical texts, some recent studies-among them Flick and Anderson (1980)indicate that in some areas the untrained native user of EST will experience the same array of decoding problems that non-native speakers do, though to a slightly lesser degree. Certainly the rhetoric and composition journals (College English. College Composition and Communication, and English Education, among others) and the technical and professional writing journals (The Technical Writing Teacher Journal of Technical Writing and Communication, Technical Communication, and Tournal of Business Communication, for example) routinely decry the EST illiteracy to be found among the general student population, along with the widespread lack of general rhetorical maturity that college writing classes are at pains to overcome. 
standing of content. For this reason, it helps if the EST instructor in the industrial setting has a solid grounding in the subject matter or can draw on native-speaker informants to explain specific technical and organizational problems that influence composing decisions.

\section{CONCLUSIONS: IMPLICATIONS FOR TEACHING}

What can EST teachers glean from this juxtaposition of the research literature on EST and the special realities of teaching EST in industry? I would offer the following five insights in closing:

1. A pressing need to teach more deliberate audience analysis. If EFL teachers can be expected to raise fundamental questions about technical texts, then non-native writers of technical documents need to be taught to take into account the comparable handicaps of coworkers, who are likely to vary markedly in their technical knowledge, organizational perspective, familiarity with the issue at hand, interest in the subject, and motivation for reading the document itself. The EST writer particularly needs to ask, for every writing task, "Who are my likely readers?" and "What features must I master to make my writing unambiguous and accessible, even to diverse audiences, without including more than is necessary?"

2. The need for using authentic texts in teaching, including specimens of the non-native professionals' own on-the-job writing and positive examples of the kinds of technical documents they are expected to emulate. Classroom use of all texts should include consideration of specific organizational contexts: the who, what, where, when, and why of each writing scenario.

3. The need for relating writing instruction to consequences for the reader, rather than to rules for the writer to follow.

4. The need for linking sentence-level concerns (syntax, lexis, mechanics, and the conventions of the print code) with higher-level composing decisions through attention to both the overall rhetorical purpose and the contributing or "shading" rhetorical purposes of every document under consideration. It is extremely useful for EST learners to practice looking for and identifying the overlapping purposes of sample documents in the classroom or writing workshop. The sensitivity they develop as attentive readers will be helpful to them when they shift to the writing role.

5. The need to demonstrate to learners that what is not said can be as informative and crucial as what is said, and the need to teach the means by which rhetorical information can be conveyed both verbally and paraverbally, explicitly and implicitly. This aspect of 
rhetorical control involves such devices as the sequencing of information, juxtaposition, punctuation, parallel structure, layout, paragraphing, repetition, contextual paraphrase, and enumeration.

The growing presence of Mai Chungs in the American workplace invites an educational response. The challenge to teachers of technical writing will be to adapt teaching methods for the growing numbers of non-native English-speaking learners. The challenge for research into language learning will be two-fold: to further illuminate the cognitive processes that go into composing and comprehending technical discourse and to identify more precisely the structures and rhetorical patterns that are characteristic of the genre.

\section{THE AUTHOR}

Sheryl Pearson is Director of the Writing Program and Assistant Professor of Rhetoric and Composition at the University of Michigan, Dearborn. She teaches EFL, technical writing, and organizational communication. She has an M.A. in Linguistics (TEFL) and a Ph.D. in English from the University of Michigan. She has taught English language and literature in Chile and Peru.

\section{REFERENCES}

de Beaugrande, Robert. 1977. Information and grammar in technical writing. College Composition and Communication 28 (4):325-332.

Chesser, Thomas M. 1981. Foreigners snap up the high-tech jobs. The New York Times 130 (44996: 5 July):13.

Dubin, Fraida, and Elite Olshtain. 1980. The interface of writing and reading. TESOL Quarterly 14 (3):353-363.

Flick, William C., and Janet Anderson. 1980. Rhetorical difficulty in scientific English: a study in reading comprehension. TESOL Quarterly 14 (3):345351.

Friedrich, Otto. 1983. Glork! A glossary for gweeps. Time 121 (1):39.

Greer, William. 1983. Foreign students: boon or a threat? The New York Times 132 (45630: 27 March) :72-73.

Lackstrom, John, Larry Selinker, and Louis Trimble. 1970. Grammar and technical English. In English as a second language: current issues, Robert Lugton (Ed.), 101-133. Philadelphia: Center for Curriculum Development.

Lackstrom, John, Larry Selinker, and Louis Trimble. 1973. Technical rhetorical principles and grammatical choice. TESOL Quarterly 7 (2):127-136.

Mathes, J. C. 1980. Technical communication, the persuasive purpose. English in Texas Summer:81-83. 
Mathes, J. C., and Dwight Stevenson. 1976. Designing technical reports: writing for audiences in organizations. One Volume and Instructor's Manual. Indianapolis: Bobbs-Merrill.

Peer, Elizabeth, and Lucy Howard. 1980. Help wanted: engineers. Newsweek 96 (20):87.

Roberts, Lori. 1981. The design and development of a technical English course. Paper presented at the 7th Annual Michigan TESOL Conference, October, 1981.

Scully, Malcolm. 1982. Foreign enrollment at U.S. colleges: the pace slows. Chronicle of Higher Education 25 (8):2.

Selinker, Larry. 1979. On the use of informants in discourse analysis and "language for specialized purposes." International Review of Applied Linguistics in Language Teaching 17 (3):189-215.

Selinker, Larry, Louis Trimble, and Robert Vroman. 1974. Presupposition and technical rhetoric. English language Teaching Journal 29 (1):59-65.

Selinker, Larry, R.M. Todd Trimble, and Louis Trimble. 1976. Presuppositional rhetorical information in EST discourse. TESOL Quarterly 10 (3):281-290.

Selinker, Larry, Mary Todd-Trimble, and Louis Trimble. 1978. Rhetorical function-shifts in EST discourse. TESOL Quarterly 12 (3):311-320.

Stevenson, Dwight. 1977. Toward a rhetoric of scientific and technical discourse. The Technical Writing Teacher 5 (1):4-9.

Young, Richard. 1979. Order and disorder in units beyond the sentence. In Proceedings of an intensive short course in written communication for engineers, scientists, and technical writers, item 11/13, Thomas M. Sawyer (Ed.). Ann Arbor: The University of Michigan. 